Chapter 7

\title{
Social Anxiety Disorder in Psychosis: A Critical Review
}

\author{
Maria Michail \\ Additional information is available at the end of the chapter \\ http://dx.doi.org/10.5772/53053
}

\section{Introduction}

Eugene Bleuler was one of the first to emphasize the importance of affect and its pronounced impact upon the course and outcome of psychosis. The famous "Krapelian dichtoco$m y$ " which supported the clear distinction between mood and psychotic illnesses on the basis of etiological origins, symptomatology, course and outcome was first challenged by Bleuler. Bleuler recognized the disorders of affect as one of the four primary symptoms (blunted 'Affect', loosening of 'Associations', 'Ambivalence', and 'Autism') of schizophrenia, as opposed to delusions and hallucinations which were perceived as secondary. Bleuler further postulated the incongruity between emotions and thought content in people with schizophrenia as well as their diminished or complete lack of emotional responsiveness. Bleuler's recognition of the importance of affective disturbances in schizophrenia has influenced current diagnostic definitions and criteria of schizophrenia.

The sharp distinction between affect and psychosis which has dominated both research and clinical practice during the nineteenth and twentieth century has gradually been abandoned. New evidence from epidemiological, familial and molecular genetic studies (Cardno et al, 2005; Craddock et al, 2005; Craddock \& Owen, 2005) have come to light demonstrating the endemic nature of affective disturbances in psychosis. In a twin study by Cardno et al (2002), the authors identified significant overlap in risk factors between the schizophrenic, schizoaffective and manic syndromes. Specifically, considerable genetic correlations were reported between the schizophrenic and manic syndromes. This is in accordance with a review of genetic linkage studies of schizophrenia and affective disorders (Wildenauer et al, 1999) which supports the genetic overlap of the two syndromes. Furthermore, factor analytic studies of psychosis symptoms consistently point to a depression dimension in non-affective psychosis (Murray et al, 2005). Depression and social anxiety are each observed throughout the course (Koreen et al, 1993), including the prodromal phase (Hafner et al, 1999; Owens et al, 2005) and following symptomatic recovery. Post psychotic depression 
(PPD) has been reported in 30-50\% of individuals (McGlashan et al, 1976; Birchwood et al, 2000a) and social anxiety disorder ( $\mathrm{SaD}$ ) has been observed in up to one in three (Davidson et al, 1993; Cassano et al, 1999; Goodwin et al, 2003; Pallanti et al, 2004).

\section{Social anxiety disorder}

\subsection{Definition}

According to the DSM-IV (APA, 1994), social anxiety disorder (social phobia) is defined as "a marked and persistent fear of one or more social or performance situations in which the person is exposed to unfamiliar people or possible scrutiny by others. The individual fears that he or she will act in a way (or show anxiety symptoms) that will be humiliating or embarrassing". People with social anxiety desire to make a favourable impression during social encounters but at the same time doubt their ability to do so; they fear that they will be scrutinized and negatively evaluated due to perceived failed social performance. These fears lead people with social anxiety to avoid all or some social situations and in extreme cases this could lead to complete social isolation (Clark \& Wells, 2005). Exposure to the feared situation is almost always accompanied by physical symptoms, for example, sweating, trembling, heart racing, which could develop (although not necessarily) to panic attacks.

Evidence regarding the distinction of social phobia into two subtypes, the non-generalized and generalized social phobia, is ambiguous; although the DSM-IV does acknowledge the presence of the latter. This encompasses a wider range of fears linked to interaction situations and therefore is not restricted to particular environmental circumstances (i.e. it is "freefloating"). It may include talking to others, asking questions, meeting new people, manifest in fear and avoidance of everyday situations (Wittchen et al, 1999). These kinds of social fears have been exclusively reported in approximately two-third of people with lifetime social phobia indicating that the generalized subtype might be more prevalent compared to the non-generalized one (Kessler et al, 1998). This, sometimes also called "specific" or "dis-

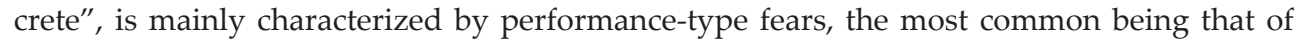
speaking in public or performing in front of an audience (Schneier et al, 1992; Stein et al, 1996). It seems therefore that the generalized subtype reflects a more pervasive and debilitating form of the illness which is supported by evidence showing higher rates of comorbidity with mood and other anxiety disorders (Wittchen et al, 1999) and lower recovery rates, compared to the non-generalized, specific subtype (Kessler et al, 1998).

\subsection{Epidemiology and course}

One of the largest epidemiological investigations carried out in the United States, the National Comorbidity Survey (Kessler et al, 1994), has reported prevalence estimates of 12month and lifetime social anxiety disorder as $7.1 \%$ and $12.1 \%$, respectively. The lifetime prevalence of social anxiety in other western countries seems to range between $3.1 \%$ to 15.6 \% (Favarelli et al, 2000; Furmark et al, 1999). The variation in prevalence rates among differ- 
ent epidemiological studies could be attributed to the application of different diagnostic criteria and instruments for the identification and assessment of social anxiety disorder.

Studies investigating the course of social anxiety have established the long-term morbidity of the illness (Chartiers et al, 1998; Yonkers et al, 2001). Social anxiety develops at an early age, usually during childhood or adolescence and once established, follows a stable, chronic course if treatment is not initiated (Chartiers et al, 1998; Yonkers et al, 2001). Recent findings show that social anxiety is also very prevalent in later life (Cairney et al, 2007). Findings regarding the sociodemographic characteristics of social anxiety disorder support that this is more prominent among the female population (Wittchen et al, 1999; Schneier et al, 1992; Davidson et al, 1993; Magee et al, 1996) although there have been studies (Stein et al, 2000) which have failed to confirm such gender differences. Moreover, higher incident rates have been consistently observed among unmarried individuals usually coming from a lower socioeconomic background, with poorer educational attainment and higher unemployment rates (Schneier et al, 1992; Davidson et al, 1993; Magee et al, 1996). The average duration of illness is approximately 29 years (Chartier et al, 1991; Keller et al, 2003) and the likelihood of a full remission or recovery is significantly lower compared to that of other anxiety disorder (Keller et al, 2003). In an eight year longitudinal study of 163 patients with social phobia, Yonkers et al (2001) found that only 38\% and 32\% of female and men respectively experienced a complete remission indicating the unremitting and persisting nature of the disorder. Additionally, such lower rates of recovery were found to be associated, particularly in women, with a history of suicide attempts, the presence of co-morbid disorders, the most prominent that of agoraphobia, avoidant personality disorder and alcohol abuse, and also with poor baseline functioning (Yonkers et al, 2001; Keller et al, 2003).

The highly impairing nature of the disorder is reflected in the marked disabilities affecting the majority of life domains. Deterioration of social functioning manifest in avoidance and withdrawal from social interactions, decrease in work productivity and interpersonal relations produce a significant decrease in quality of life (Wittchen et al, 2000). Despite the highly impairing nature of social anxiety only up to a half of patients seek and receive treatment during the course of the illness (Wittchen et al, 2000; Wang et al, 2005) and this is primarily in the form of pharmacological interventions.

\section{Social anxiety in psychosis}

Social anxiety is among the most prevalent and debilitating affective disturbances manifest in people with psychosis (Pallanti et al, 2004; Mazeh et al, 2009; Michail \& Birchwood, 2009). In a recent study by Michail \& Birchwood (2009), social anxiety was diagnosed in 25\% of people with first-episode psychosis (FEP). In addition to the $25 \%$ with an ICD- 10 diagnosis of SaD, there was also a further $11.6 \%$ who reported clear social interaction difficulties and/or signs of avoidance not sufficient though to reach formal diagnostic criteria. Social anxiety is usually accompanied by high levels of depression (Michail \& Birchwood, 2009; Birchwood et al, 2007) and leads to significant social disability (Voges \& Addington, 2005), lower quality of life (Pallanti et al, 2004) and poorer prognosis as it raises the possibility of an early relapse (Gumley, 2007). 
Despite the high prevalence and its debilitating nature, social anxiety has not been extensively investigated and the processes that underlie its emergence in psychosis remain unclear. The relationship between social anxiety and positive psychotic symptoms, particularly paranoia, is yet to be clarified. Particularly, it is not clear whether the development and maintenance of social anxiety in psychosis is simply driven by paranoia and persecutory beliefs.

\section{Aim}

This review aims to examine the prevalence and phenomenology of social anxiety disorder in psychosis and to investigate its relationship to positive psychotic symptoms and particularly paranoia and persecutory ideation.

\section{Methods}

A systematic search strategy was conducted and consisted of electronic searches of the following databases: PsycINFO, PubMed and Science Direct using the terms "anxiety AND psychosis", "anxiety AND schizophrenia", "social anxiety AND psychosis", "social anxiety AND schizophrenia", "social anxiety AND paranoia". For inclusion, studies had to meet the following criteria:

1. Published in an English language, peer-reviewed journal. This ensures a degree of quality assurance in the reviewing process

2. Published between 1990-2011

3. Participants with psychosis. This includes schizophrenia, schizoaffective disorder, schizophreniform, bipolar disorder and depression with psychotic features

4. Adult participants ( $\geq 16$ years)

5. Diagnosis of social anxiety disorder (either ICD-10 or DSM-IV)

Following the electronic search, hand searches of identified literature were conducted in the form of citation chasing.

\section{Results}

Thirteen studies fulfilled the inclusion criteria of this review (Table 1): three studies (Cossof \& Hafner, 1998; Tibbo et al, 2003; Braga et al, 2005) investigated the prevalence of anxiety disorders, (including social anxiety) in psychosis; six examined the prevalence of social anxiety disorder in psychosis (Penn et al, 1994; Pallanti et al, 2004; Voges \& Addington, 2005; Birchwood et al, 2007; Mazeh et al, 2009; Michail \& Birchwood et al, 2009), three studies (Lysaker \& Ham- 
mersley, 2006; Lysaker \& Salyers; 2007; Romm et al, 2012) investigated the relationship of social anxiety with clinical psychotic symptoms and one review paper on anxiety disorders in schizophrenia was also identified (Muller et al, 2004). Four studies recruited a first-episode psychosis sample (Voges \& Addington, 2005; Birchwood et al, 2007; Michail \& Birchwood, 2009; Romm et al, 2012); three recruited in-patients with schizophrenia, schizoaffective or bipolar disorder (Cossof \& Hafner, 1998; Penn et al, 1994; Mazeh et al, 2009) and three recruited outpatients with schizophrenia (Tibbo et al, 2003; Braga et al, 2005; Pallanti et al, 2004).

\subsection{Prevalence and phenomenology}

Social anxiety appears to be among the most prevalent anxiety disorders in psychosis with prevalence rates ranging between $17 \%$ to $36 \%$. In samples with first-episode psychosis, prevalence rates range between $25 \%-32 \%$ based on formal diagnostic criteria (DSM-IV or ICD-10). In a recent study by Michail \& Birchwood (2009), social anxiety was diagnosed in $25 \%$ of people with first-episode psychosis. However, in addition to the $25 \%$ with formal SaD, there was also a further $11.6 \%$ who reported clear social interaction difficulties and/or signs of avoidance not sufficient though to reach formal diagnostic criteria (ICD-10). These "borderline" cases, though not satisfying formal criteria, were nevertheless reporting interpersonal difficulties that may well warrant intervention at a clinical level. In studies with inpatient samples, the prevalence of social anxiety ranged between $11 \%-43 \%$ among those with schizophrenia, schizoaffective or bipolar disorder and in studies with outpatients with schizophrenia $17 \%-36 \%$ of them were diagnosed with social anxiety disorder or social phobia.

The highly impairing nature of social anxiety in psychosis has been consistently reported in literature. In a study of outpatients with schizophrenia, Pallanti et al (2004) reported that those diagnosed with comorbid social anxiety disorder had a higher rate of suicide attempts, lower social adjustment and overall quality of life compared to those without social anxiety. Braga et al (2005) also reported higher levels of global functional impairment and greater limitations in the domains of work and social life in schizophrenic patients with comorbid anxiety disorder compared to those without comorbid anxiety disorder. Previous findings by Penn et al (1994) confirm the significant impact of social anxiety on social disability. Findings also show that those with schizophrenia and comorbid social anxiety have higher levels of substance abuse compared to those with no comorbid social anxiety (Pallanti et al, 2004).

The phenomenology of social anxiety in psychosis has been thoroughly investigated by Michail \& Birchwood (2009). In their study comparing the severity and phenomenology of social anxiety in psychosis with that in non psychosis, the authors revealed a very similar clinical profile with regards to levels of social anxiety and social avoidance; the number and severity of autonomic anxiety symptoms and social evaluative concerns. What is more, social anxiety both in people with psychosis and non psychosis occurred in the context of an equally high level of other anxiety disorders underlying the similarity of the two groups. The presence of social anxiety in people with psychosis was also accompanied by marked levels of depression; approximately $31 \%$ of FEP people exhibited moderate to severe levels of post-psychotic depression. This is in line with findings from previous studies (Voges \& Addington, 2005; Birchwood et al, 2007) and confirmed by Romm et al (2012) who found that high levels of social anxiety in people with first-episode psychosis were accompanied by high levels of depression. 


\begin{tabular}{|c|c|c|c|}
\hline Study & Participants & Aim & Key results \\
\hline$\overline{\text { Penn et al. (1994) }}$ & $\begin{array}{l}38 \text { in-patients with a } \\
\text { diagnosis of schizophrenia or } \\
\text { schizoaffective disorder } \\
\text { according to the SCID-P }\end{array}$ & $\begin{array}{l}\text { Investigate the relationship } \\
\text { rbetween social anxiety and } \\
\text { positive and negative } \\
\text { symptoms in schizophrenia }\end{array}$ & $\begin{array}{l}\text { Behavioural indices of social anxiety (e.g. slower } \\
\text { speech rated, less fluent speech, global social } \\
\text { anxiety) were associated with negative } \\
\text { symptoms. Self-report measures of social } \\
\text { anxiety and related fears (e.g. fear of being } \\
\text { negatively evaluated, fear of walking alone in } \\
\text { the streets, fear of talking to people in } \\
\text { authority) were associated with positive } \\
\text { symptomatology. Such fears may be related to } \\
\text { certain aspects of the illness e.g. paranoia, } \\
\text { persecutory ideation whereas behavioural } \\
\text { manifestations of social anxiety may reflect a } \\
\text { deficit in social skills prominent in negative } \\
\text { symptom }\end{array}$ \\
\hline Cossof \& Hafner (1998) & $\begin{array}{l}100 \text { consecutive in-patients } \\
\text { diagnosed with } \\
\text { schizophrenia, } \\
\text { schizoaffective disorder or } \\
\text { bipolar disorder(based on } \\
\text { the SCID) }\end{array}$ & $\begin{array}{l}\text { Determine the prevalence of } \\
\text { anxiety disorders in treated } \\
\text { psychiatric inpatients with a } \\
\text { DSM-IV diagnosis of } \\
\text { schizophrenia, schizoaffective } \\
\text { or bipolar disorder }\end{array}$ & $\begin{array}{l}43 \% \text { of inpatients with schizophrenia were also } \\
\text { diagnosed with a comorbid anxiety disorder } \\
\text { (based on the SCID): } 17 \% \text { social phobia (SP), } \\
12 \% \text { generalized anxiety disorder (GAD), } 13 \% \\
\text { eobsessive-compulsive disorder (OCD) }\end{array}$ \\
\hline Tibbo et al (2003) & $\begin{array}{l}30 \text { outpatients with a } \\
\text { diagnosis of DSM-IV } \\
\text { schizophrenia (based on the } \\
\text { MINI) }\end{array}$ & $\begin{array}{l}\text { Determine the prevalence of } \\
\text { anxiety disorders (as assessed } \\
\text { by the MINI) controlling for } \\
\text { anxiety symptoms related to } \\
\text { delusions and hallucinations }\end{array}$ & $\begin{array}{l}\text { 16.7\% prevalence of GAD } \\
13.3 \% \text { prevalence of SP } \\
\text { 3.3\% prevalence of panic disorder with/without } \\
\text { agoraphobia } \\
16.7 \% \text { prevalence of agoraphobia without } \\
\text { panic, } \\
\text { excluding individuals whose anxiety symptoms } \\
\text { were related to delusions or hallucinations }\end{array}$ \\
\hline Muller et al (2004) & $\begin{array}{l}\text { A review of the literature on } \\
\text { comorbid anxiety disorders } \\
\text { in schizophrenia }\end{array}$ & $\begin{array}{l}\text { Review the epidemiology, } \\
\text { phenomenology, } \\
\text { and neurobiologic } \\
\text { underpinnings of comorbid } \\
\text { anxiety symptoms } \\
\text { and disorders in } \\
\text { schizophrenia, and address } \\
\text { treatment } \\
\text { strategies }\end{array}$ & $\begin{array}{l}\text { Anxiety disorders are very prevalent in } \\
\text { schizophrenia. The mechanisms that underpin } \\
\text { this comorbidity require further investigation. } \\
\text { Randomized controlled trials of } \\
\text { pharmacotherapy and psychotherapy are } \\
\text { necessary to establish the best way of } \\
\text { managing this comorbidity }\end{array}$ \\
\hline Pallanti et al (2004) & $\begin{array}{l}80 \text { outpatients with } \\
\text { schizophrenia (based on the } \\
\text { SCID for DSM-IV) and } 27 \\
\text { outpatients with primary } \\
\text { diagnosis of social anxiety } \\
\text { disorder }\end{array}$ & $\begin{array}{l}\text { Prevalence and severity of } \\
\text { social anxiety in } \\
\text { schizophrenia } \\
\text { Compare the severity and } \\
\text { phenomenology of social } \\
\text { anxiety in those with } \\
\text { schizophrenia and those with } \\
\text { social anxiety as primary } \\
\text { diagnosis (no schizophrenia) }\end{array}$ & $\begin{array}{l}\text { 36.3\% of people with schizophrenia were } \\
\text { diagnosed with social anxiety based on the } \\
\text { Liebowitz Social Anxiety Scale (LSES). The } \\
\text { severity of social anxiety and avoidance in this } \\
\text { group was as elevated in those with social } \\
\text { anxiety without schizophrenia } \\
\text { People with social anxiety and schizophrenia } \\
\text { had a higher rate of suicide attempts, lower } \\
\text { social adjustment and overall quality of life } \\
\text { compared to those with schizophrenia only } \\
\text { No differences in positive and negative } \\
\text { symptoms (as assessed by the SAPS and SANS) } \\
\text { between patients with schizophrenia and social } \\
\text { anxiety and those with schizophrenia only }\end{array}$ \\
\hline
\end{tabular}




\begin{tabular}{|c|c|c|c|}
\hline Study & Participants & Aim & Key results \\
\hline Voges \& Addington (2005) & $\begin{array}{l}60 \text { patients with first- } \\
\text { episode psychosis (FEP) }\end{array}$ & $\begin{array}{l}\text { Examine the relationship } \\
\text { between social anxiety and } \\
\text { social functioning and } \\
\text { determine whether those } \\
\text { with psychosis have any } \\
\text { maladaptive or irrational } \\
\text { beliefs regarding } \\
\text { social situations }\end{array}$ & $\begin{array}{l}32 \% \text { of patients with FEP were diagnosed with } \\
\text { social anxiety disorder (SCID-I for DSM-IV) } \\
\text { Higher levels of social anxiety, as assessed by } \\
\text { the Social Phobia and Anxiety Inventory (SPAI) } \\
\text { were related to depression and negative } \\
\text { symptoms but not positive symptoms. } \\
\text { Social anxiety was associated with greater } \\
\text { negative self-statements, and the lack of social } \\
\text { anxiety with higher levels of positive self- } \\
\text { statements. The authors suggest that negative } \\
\text { self-statements may be prominent in the } \\
\text { development and maintenance of social anxiety } \\
\text { in first-episode patients }\end{array}$ \\
\hline Braga et al (2005) & $\begin{array}{l}53 \text { outpatients with a DSM- } \\
\text { IV diagnosis of schizophrenia }\end{array}$ & $\begin{array}{l}\text { Describe the prevalence of } \\
\text { acomorbid lifetime anxiety } \\
\text { disorders in outpatients with } \\
\text { schizophrenia and to } \\
\text { compare the } \\
\text { subjective quality of life of } \\
\text { patients with and without } \\
\text { comorbid anxiety disorders }\end{array}$ & $\begin{array}{l}\text { Prevalences of anxiety comorbidity (based on } \\
\text { SCID-IV) were: social phobia (17\%), OCD } \\
(15.1 \%), \text { GAD (9.4\%), anxiety disorder } \\
\text { Not Otherwise Specified (7.5\%), panic disorder } \\
(5.7 \%) \text {, specific phobia ( } 5.7 \%) \text {, Post-traumatic } \\
\text { stress disorder (PTSD) (3.8\%), and agoraphobia } \\
(1.9 \%) \\
\text { Higher levels of global functional impairment, } \\
\text { more severe limitations in the domains of work } \\
\text { and social life in schizophrenic patients with } \\
\text { comorbid anxiety disorder compared to those } \\
\text { without comorbid anxiety disorder }\end{array}$ \\
\hline Birchwood et al (2007) & $\begin{array}{l}79 \text { participants with first- } \\
\text { episode psychosis }\end{array}$ & $\begin{array}{l}\text { 1. Examine the rate and } \\
\text { severity of social anxiety in } \\
\text { FEP } \\
\text { 2. investigate the relationship } \\
\text { of social anxiety with positive } \\
\text { and negative symptoms } \\
\text { 3. investigate the relationship } \\
\text { between social anxiety and } \\
\text { shame of psychosis }\end{array}$ & $\begin{array}{l}29 \% \text { prevalence of social anxiety in FEP (based } \\
\text { on the SIAS/SPS) } \\
\text { No relationship between delusions, } \\
\text { hallucinations and suspiciousness/ persecution } \\
\text { and social anxiety (based on the positive scale } \\
\text { of PANSS). Also, no relationship between } \\
\text { negative symptoms and social anxiety and } \\
\text { avoidance } \\
\text { Greater levels of shame attached to their } \\
\text { diagnosis and feelings of being down-ranked } \\
\text { and rejected in the socially anxious psychotic } \\
\text { group compared to the non socially anxious } \\
\text { psychotic group }\end{array}$ \\
\hline Mazeh et al (2009) & $\begin{array}{l}117 \text { inpatients with a SCID-P } \\
\text { for DSM-IV diagnosis of } \\
\text { schizophrenia }\end{array}$ & $\begin{array}{l}\text { Investigate the prevalence } \\
\text { and correlates of social } \\
\text { phobia in patients with } \\
\text { schizophrenia }\end{array}$ & $\begin{array}{l}\text { 11\% were diagnosed with comorbid social } \\
\text { phobia (based on the SCID-P) } \\
\text { Schizophrenic patients with comorbid social } \\
\text { phobia had higher (although not statistically } \\
\text { significant) level of PANSS total score compare } \\
\text { to those without social phobia } \\
\text { The "fear" component of social phobia (as } \\
\text { measured by the Leibowitz Social Anxiety Scale, } \\
\text { LSAS) was related to positive psychotic } \\
\text { symptoms } \\
\text { Avoidance (as measured by LSAS) was } \\
\text { associated with negative symptoms }\end{array}$ \\
\hline
\end{tabular}




\begin{tabular}{|c|c|c|c|}
\hline Study & Participants & Aim & Key results \\
\hline Michail \& Birchwood (2009) & 80 participants with FEP & $\begin{array}{l}\text { Determine the } \\
\text { phenomenology of psychotic } \\
\mathrm{SaD} \text { and how this is different } \\
\text { to non-psychotic SaD } \\
\text { Investigate whether } \\
\text { psychotic SaD is linked to the } \\
\text { nature and severity of } \\
\text { psychotic symptoms and } \\
\text { particularly paranoia }\end{array}$ & $\begin{array}{l}\text { 25\% of FEPs received an ICD-10 diagnosis of } \\
\text { social anxiety based on the SCAN (WHO, 1999). } \\
\text { Equally elevated levels of social anxiety (SIAS), } \\
\text { avoidance (SPS), depression (CDSS) and } \\
\text { autonomic anxiety symptoms in the psychotic } \\
\text { and non psychotic socially anxious group } \\
\text { No relationship between positive symptoms } \\
\text { including suspiciousness/persecution (PANSS) } \\
\text { and social anxiety (SIAS/SPS) in the FEP group. } \\
\text { However, a subgroup of socially anxious } \\
\text { psychotic people reported higher levels of } \\
\text { persecutory threat (Details of Threat } \\
\text { Questionnaire) compared to psychotic people } \\
\text { without social anxiety. }\end{array}$ \\
\hline Romm et al (2012) & $\begin{array}{l}144 \text { participants with FEP } \\
\text { (based on SCID-I for DSM-IV) }\end{array}$ & $\begin{array}{l}\text { Investigate whether SaD in } \\
\text { psychosis is associated with } \\
\text { poorer premorbid } \\
\text { functioning, higher levels of } \\
\text { psychotic symptoms and } \\
\text { reduced QoL }\end{array}$ & $\begin{array}{l}\text { 50\% of FEPs suffered from severe social anxiety } \\
\text { (LSAS). Social anxiety was associated with } \\
\text { greater levels of depression, poorer premorbid } \\
\text { functioning and reduced QoL. No relationship } \\
\text { between social anxiety and positive psychotic } \\
\text { symptoms was reported. }\end{array}$ \\
\hline Lysaker \& Salyers (2007) & $\begin{array}{l}128 \text { participants with } \\
\text { schizophrenia \& } \\
\text { schizoaffective disorder } \\
\text { (based on SCID for DSM-IV) }\end{array}$ & $\begin{array}{l}\text { Investigate the relationship } \\
\text { between anxiety (as } \\
\text { measured by the } \\
\text { Multidimensional Anxiety } \\
\text { Questionnaire) and psychotic } \\
\text { symptoms (as measured by } \\
\text { the PANSS) }\end{array}$ & $\begin{array}{l}\text { Higher levels of anxiety were associated with } \\
\text { greater hallucinations, withdrawal, depression, } \\
\text { hopelessness, better insight and poorer } \\
\text { function. } \\
\text {. }\end{array}$ \\
\hline Lysaker \& Hammersley (2006) & $\begin{array}{l}71 \text { participants with } \\
\text { schizophrenia \& } \\
\text { schizoaffective disroder }\end{array}$ & $\begin{array}{l}\text { Examine the possible roots of } \\
\text { social anxiety in } \\
\text { schizophrenia by } \\
\text { investigating its relationship } \\
\text { to delusions and flexibility of } \\
\text { abstract thought }\end{array}$ & $\begin{array}{l}\text { f Participants classified as having both significant } \\
\text { delusions (based on the PANSS) and } \\
\text { impairments in flexibility of abstract thought } \\
\text { had significantly higher levels of social anxiety } \\
\text { (based on the LSAS) compared to those with } \\
\text { only one or neither of these difficulties }\end{array}$ \\
\hline
\end{tabular}

Table 1. Studies investigating social anxiety in people with psychosis

\subsection{The relationship between social anxiety and positive psychotic symptoms}

The relationship between social anxiety and positive psychotic symptoms, particularly paranoia, has attracted considerable attention; however, the processes that underlie this relationship are yet to be clarified. Ten studies identified in this review examined the relationship of social anxiety with positive symptoms (Penn et al, 1994; Tibbo et al, 2003; Pallanti et al, 2004; Voges \& Addington, 2005; Birchwood et al, 2007; Mazeh et al, 2009; Michail \& Birchwood, 2009; Lysaker \& Hammersley, 2006; Lysaker \& Salyers, 2007; Romm et al, 2012). Four studies (Penn et al, 1994; Mazeh et al, 2009; Lysaker \& Hammersley, 2006; Lysaker \& Salyers, 2007) reported a link between social anxiety and positive symptoms. Penn et al (1994) showed that self-report measures of social anxiety and related fears (e.g. fear of being negatively evaluated, fear of walking alone in the streets, fear of talking to people in authority) were associated with positive symptomatology. The authors suggested that such fears may be related to cer- 
tain aspects of the illness e.g. paranoia, persecutory ideation whereas behavioural manifestations of social anxiety (e.g. slower speech rated, less fluent speech, global social anxiety) may reflect a deficit in social skills prominent in negative symptoms. This was also supported by Mazeh et al (2009) who found the "fear" component of social phobia in schizophrenic patients (as measured by the Leibowitz Social Anxiety Scale, LSAS) to be related to positive psychotic symptoms. Lysaker \& Hammersley (2006) and Lysaker \& Salyers (2007) found that in people with schizophrenia severe social anxiety was accompanied by severe levels of delusions and greater levels of hallucinations, respectively.

Five studies (Pallanti et al, 2004; Voges \& Addington, 2005; Birchwood et al, 2007; Michail \& Birchwood, 2009, Romm et al, 2012) reported no differences in severity levels of positive symptoms (including paranoia) between those with schizophrenia and comorbid SaD vs no $\mathrm{SaD}$, suggesting that $\mathrm{SaD}$ may be unrelated to clinical psychotic symptoms. In a study of young people with first-episode psychosis, Michail \& Birchwood (2009) conducted a thorough investigation of the relationship between positive symptoms and social anxiety. The authors compared levels of positive symptoms, including suspiciousness and persecution, as measured by the PANSS (Positive and Negative Symptom Scale) between people with psychosis and social anxiety (FEP/SaD) and those with psychosis only (FEP/no SaD). Findings revealed no differences in PANSS positive symptoms between psychotic individuals with vs. without social anxiety; including no relationship between PANSS suspiciousness/ persecution and social anxiety in the whole FEP (with and without SaD) sample. Furthermore, the level of PANSS suspiciousness/persecution did not affect the severity of social anxiety within the FEP/SaD group itself. These findings confirm previous studies reporting no link between positive symptoms (similarly assessed using the PANSS) and social anxiety (Pallanti et al, 2004; Voges \& Addington, 2005) which suggests that the presence of social anxiety in psychosis is not simply driven by clinical paranoia and persecutory threat. It is important to mention though findings in the Michail \& Birchwood (2009) study also revealed a subgroup of socially anxious psychotic people (45\%) which reported significantly more persecutory threat and anticipated harm as measured by the Details of Threat Questionnaire (Freeman et al, 2001) compared to psychotic people without social anxiety. When investigating further the inter-relationship between social anxiety and persecutory threat within this sub-group no link between level of social anxiety and persecutory threat was revealed. This is of particular interest as it suggests that even among those individuals with psychosis and social anxiety, social anxiety is not necessarily contaminated by ongoing persecutory beliefs.

\section{Discussion}

Social anxiety is among the most commonly reported and disabling of the co-morbidities in people with psychosis. It is characterized by a highly impairing nature which is evident by its impact on social functioning and social disability. Despite its elevated prevalence and severity in psychosis, social anxiety remains under-recognized and under-treated. One of the reasons for this could be that the exact relationship between social anxiety and psychotic 
symptoms is yet to be determined and the available empirical findings are inconclusive. Although theoretical models and empirical evidence consistently point towards a link between general anxiety and positive symptoms of psychosis, predominantly paranoia and persecutory delusions (Freeman et al, 2001), social anxiety appears to have a distinct quality and its relationship to paranoia and persecutory thinking is not straightforward.

Three pathways have been proposed for the understanding of the ontogeny of social anxiety in psychosis (Michail \& Birchwood, 2009; 2011) and they are summarized here:

a. social anxiety predates the onset of paranoia and helps maintain persecutory beliefs

This suggests that symptoms of social anxiety, avoidance and withdrawal develop in the early or prodrome phase. This is confirmed by studies showing how social withdrawal and socio-emotional dysfunction in people identified as being at risk for developing psychosis are highly predictive predicting of psychosis (Johnstone et al, 2005; Miller et al, 2002; Yung et al, 2004). The development of paranoia and persecutory ideation follows the onset of social anxiety which serves the function of maintaining or strengthening persecution ideation. The work by Freeman et al (2005a; 2005b) has shown how common social anxieties, for example, fear of rejection, interpersonal sensitivity and negative beliefs about the self are amongst the most commonly reported types of suspiciousness (2005a) and form the basis upon which ideas of reference and more severe levels of paranoid thinking are established. Furthermore, these anxieties and social evaluative concerns were found to predict paranoid thinking in a non-clinical sample (2005b).

b. social anxiety and paranoia develop concurrently in the early phase of psychosis and follow a similar course

This pathway suggests that for a sub-group of individuals, social anxiety and paranoia may develop at the same time and follow a similar course. According to Freeman et al (2001), social anxiety and paranoia are underlined by common fears and concerns which refer to the anticipation of threat and danger which drives behaviours of avoidance and withdrawal from social interactions. It is expected therefore that for this sub-group of people, addressing paranoid concerns and ideas of persecution, would inevitably lead to the remission of symptoms of social anxiety and avoidance.

c. social anxiety may develop for some people as a consequence of paranoid beliefs

The third pathway suggests that for a sub-sample of people with psychosis, symptoms of social anxiety and avoidance may develop as a direct consequence of their paranoid ideation. Persecutory beliefs and perceived threat regarding other people's intentions to cause harm can lead to elevated social anxiety and apprehension during social encounters. As a way of protecting or "saving" oneself from such social threats, individuals may engage in safety behaviours by isolating themselves from the social world and actively avoiding all social interactions.

Following the findings of a thorough investigation into the psychological processes that underlie the emergence and maintenance of social anxiety in psychosis (Michail \& Birchwood, 2012), a fourth potential pathway is provided here: 
d. social anxiety as a response to the shame and social stigma attached to a diagnosis of mental illness

In a recent study by Michail \& Birchwood (2012), the authors examined the relationship between shame cognitions, shame proneness and perceived loss of social status in people with first-episode psychosis and social anxiety disorder. Findings showed that psychotic individuals with social anxiety expressed high levels of shame proneness which was accompanied by perceived loss of social status. They also reported significantly greater negative appraisals arising from a stigmatizing illness, including shame and fear of rejection, compared to their counterparts without social anxiety. These findings were consistent with those of earlier studies (Birchwood et al, 2007, Gumley et al, 2004) reporting that dysfunctional appraisals held by socially anxious psychotic people were characterized by shamefulness, humiliation and perceived rejection by others.

The authors proposed that individuals with psychosis are characterized by an established vulnerability to shame linked to early developmental anomalies. This shame proneness is likely to be catalysed by the stigma attached to the diagnosis of mental illness and there is evidence to suggest that psychosis is indeed considered as a highly stigmatized condition (Thornicroft et al, 2009). As with any type of social stigma, this can affect the social identity of the individual by suggesting qualities that deviate from the norm and are socially discrediting (Goffman, 1963). Individuals with psychosis are aware of the social stereotypes surrounding mental illness and some may even accept and endorse these (Hayward \& Bright, 1997; Angermeyer et al, 2003). This internalization of stigma or self-stigma leads to increased shamefulness -particularly when individuals agree with the stigma and the associated negative responses (Corrigan \& Watson, 2002a; 2002b)- and fear of the illness being revealed to others due to the consequences of this discovery (e.g. social exclusion, marginalization). Hence, the authors suggested that people with psychosis will attempt to conceal their stigmatized identity to prevent or minimise this threat by promoting behaviours of submissiveness or by avoiding and withdrawing from social interactions.

\section{Clinical implications}

There is lack of evidence on the clinical effectiveness and cost effectiveness of psychological interventions for the treatment of affective dysregulation and associated distress in psychosis. Cognitive behaviour therapy (CBT) is recommended for people with psychosis (NICE, 2009); however, its focus and evaluation has primarily revolved around the reduction of psychotic symptoms, and not for comorbid depression and social anxiety. Furthermore, psychological interventions such as CBT for the treatment of affective disorders in non-psychotic populations are proposed for the management of affective dysfunction when this is comorbid in psychosis (Halperin et al, 2000; Kingsep et al, 2003). This could be challenging as such treatments in order to be effective, would need to adapt to the specific nature of symptoms and difficulties experienced by people with psychosis (Tarrier, 2005). The findings of the recent study by Michail \& Birchwood (2012) suggest that the "conventional" CBT 
for social anxiety in psychosis could be considerably enhanced with an additional focus on shame cognitions linked to psychosis and accompanying concealment behaviours which are suggested to form part of the safety behaviour repertoire of socially anxious psychotic individuals. A randomised controlled trial testing the effectiveness of a CBT intervention in targeting shameful cognitions while reducing or eliminating concealment linked behaviours could be effective in psychosis.

\section{Author details}

Maria Michail

Address all correspondence to: maria.michail@nottingham.ac.uk

School of Nursing, Midwifery \& Physiotherapy, University of Nottingham, UK

\section{References}

[1] American Psychiatric Association(1994). Diagnostic and statistical manual of mental health disorders (4th ed). Washington DC

[2] Angermeyer, M. C., \& Matschinger, H. (2003). The stigma of mental illness: effects of labeling on public attitudes towards people with mental disorder. Acta Psychiatrica Scandinavica, 108, 304-309.

[3] Birchwood, M., Iqbal, Z., Chadwick, P., \& Trower, P. Cognitive Approach to Depression and Suicidal Thinking in Psychosis I. Ontogeny of post-psychotic depression. British Journal of Psychiatry (2000a). , 177, 516-521.

[4] Cairney, J., Mc Cabe, L., Veldhuizen, S., Corna, L., Streiner, D., \& Herrmann, N. (2007). Epidemiology of social phobia in later life. Am J Geriatr Psychiatry, 15 (3), 224-233

[5] Cardno, A., G., , Rijsdijl, F. V., Sham, P. C., et al. (2002). A twin study of genetic relationships between psychotic symptoms. American Journal of Psychiatry, , 159, 539-545.

[6] Cassano, G. B., Pini, S., Saettoni, M., \& Dell'Oso, L. (1999). Multiple Anxiety Disorder Comorbidity in Patients with Mood Spectrum Disorders with Psychotic Features. American Journal of Psychology, , 156, 474-476.

[7] Chartier MJ, Hazen AL, Stein MB. (1998). Lifetime patterns of social phobia: a retrospective study of the course of social phobia in a nonclinical population. Depression and Anxiety, 113 EOF-21 EOF. 
[8] Clark, D., \& Wells, . (1995). A Cognitive Model of Social Phobia. In Heimberg, Liebowitz (eds.), Social Phobia. New York, Guildford Press

[9] Corrigan PW, Watson CA(2002a). The paradox of self-stigma and mental illness. Clinical Psychology and Science Practice , 9, 35-53.

[10] Corrigan PW, Watson CA(2002b). Understanding the impact of stigma on people with mental illness. World Psychiatry , 1, 16-20.

[11] Craddock, N., O’Donovan, M. C., \& Owen, M. J. (2005). Genetics of schizophrenia and bipolar disorder: dissecting of psychosis. Journal of Medical Genetics, , 42, 193-204.

[12] Craddock, N., \& Owen, M. J. (2005). The beginning of the end of the Kraepelian dichotomy. British Journal of Psychiatry, , 186, 364-366.

[13] Davidson, J., Hughes, D., George, L., \& Blazer, D. (1993). The Epidemiology of Social Phobia: Findings from the Duke Epidemiological Catchment Area Study. Psychological Medicine, 23, 709-718.

[14] Favarelli, C., Zucchi, T., Viviani, B., Salmoria, R., Perone, A., Paionni, A., Scarpato, A., Vigliaturo, D., Rosi, S., Dadamo, D., Bartolozzi, D., Cecchi, C., \& Abrardi, L. (2000). Epidemiology of Social Phobia: A Clinical Approach. European Psychiatry, , $15,17-24$.

[15] Freeman, D., Garety, P. A., \& Kuipers, E. (2001). Persecutory delusions: Developing the understanding of belief maintenance and emotional distress. Psychological Medicine, 31, 1293-1306.

[16] Freeman, D., Garety, P. A., Bebbington, P., Slater, M., Kuipers, E., Fowler, D., Green, C., Jordan, J., Ray, K., \& Dunn, G. (2005a). The psychology of persecutory ideation. II. A virtual reality exp. erimental study. Journal of Nervous Mental Disorders, , 193, 309-315.

[17] Freeman, D., Garety, P. A., Bebbington, P. E., Smith, B., Rollinson, R., Fowler, D., Kuipers, E., Ray, K., \& Dunn, G. (2005b). Psychological investigation of the structure of paranoia in a non-clinical population. Br J Psychiatry, , 186, 427-435.

[18] Furmark, T., Tillfors, M., Everz-O, P., Marteinsdottir, I., Gefrert, O., \& Fredrikson, M. (1999). Social Phobia in the General Population: Prevalence and Sociodemographic Profile. Social Psychiatry and Psychiatric Epidemiology, 34, 416-424.

[19] Goodwin, D. R., Amador, F. X., Malaspina, D., Yale, A. S., Goetz, R. R., \& Gorman, M. J. (2003). Anxiety and Substance Use Comorbidity among Inpatients with Schizophrenia. Schizophrenia Research, 61, 89-95.

[20] Gumley, A., O'Grady, M., Power, K., \& Schwannauer, M. (2004). Negative Beliefs about Self and Illness: A Comparison of Individuals with Psychosis with and without Comorbid Social Anxiety Disorde. r. Aust ranlian and New Zealand Journal of Psychiatry, , 38, 960-964. 
[21] Gumley et al(2007). Staying well after psychosis: a cognitive interpersonal approach to emotional recovery after relapse preventi. on. Tidsskrift for Norsk Psykologforening, 44 (5), 667-676

[22] Hafner, H., Loffler, W., Mauer, K., Hambrecht, M., \& an der, Heiden. W. (1999). Depression, Negative Symptoms, Social Stagnation and Social Decline in the Early Course of Schizophrenia. Acta Psychiatrica Scandinavica,, 100, 105-118.

[23] Halperin, S., Nathan, P., Drummond, P., \& Castle, D. (2000). A cognitive-behavioural, group-based intervention for social anxiety in schizophrenia. Australian and New Zealand Journal of PsychiatryHayward, P. \& Bright, J. (1997) Stigma and mental illness: a review and critique. Journal of Mental Health, 6, 345-354, 34, 809-813.

[24] Johnstone, C. E., Ebmeier, P. K., Miller, P., Owens, G. C. D., \& Lawrie, M. S. (2005). Predicting Schizophrenia: Findings from the Edinburgh High-Risk Study. British Journal of Psychiatry, , 186, 18-25.

[25] Keller, B. (2003). The lifelong course of social anxiety disorder: a clinical perspective. Acta Psychiatrica Scandinavica, 108, 85-94.

[26] Kessler, R., Murray, B., \& Berglund, M. (1998). Social Phobia Subtypes in the National Comorbidity Survey. American Journal of Psychiatry „, 155, 613-619.

[27] Kessler, R. C., Mc Gonagle, K. A., Zhao, S., Nelson, C. B., Hughes, M., Eshleman, S., Wittchen-U, H., \& Kendler, K. S. (1994). Lifetime and 12-month prevalence of DSMIII-R psychiatric disorders in the United States: results from the National Comorbidity Survey. Archives of General Psychiatry, 51, 8-19.

[28] Kingsep, P., Nathan, P., \& Castle, D. (2003). Cognitive behavioural group treatment for social anxiety in schizophrenia. Schizophrenia Research, 63, 121-129.

[29] Koreen, A., Siris, S., Chakos, M., Alvir, J., Mayerhoff, D., \& Lieberman, J. (1993). Depression in First-Episode Schizophrenia. American Journal of Psychology, , 150, 1643-1648.

[30] Magee, W. J., Eaton, W. W., Wittchen, H. U., Mc Gonagle, K. A., \& Kessler, R. C. (1996). Agoraphobia, simple phobia, and social phobia in the National Comorbidity Survey. Archives of General Psychiatry, , 53, 159-168.

[31] Mazeh et al(2009). Co-morbid social phobia in schizophrenia. International Journal of psychiatry, , 55, 198-202.

[32] Mc Glashan, T., \& Carpenter, W. (1976). An Investigation of the Post-psychotic Depressive Symptom. American Journal of Psychology, 133 (1), 14-19

[33] Michail, M., \& Birchwood, M. (2009). Social anxiety disorder in first-episode psychosis: Incidence, phenomenology and relationship with paranoia. British Journal of Psychiatry, 195, 234-241.

[34] Michail, M., \& Birchwood, M. (2011). Understanding the role of emotion in psychosis: social anxiety disorder in first-episode psychosis.. In: RITSNER, M., ed., Hand- 
book of Schizophrenia Spectrum Disorders: Phenotypic and Endophenotypic Presentations 1st. 2nd. Springer. , 89-110.

[35] Michail, M., \& Birchwood, M. (2012). Social anxiety disorder and shame cognitions in psychosis. Psychological Medicinee-pub), 1 EOF-10 EOF.

[36] Miller, P., Byrne, M., Hodges, A., Lawrie, M. S., Owens, G. C. D., \& Johnstone, C. E. (2002). Schizotypal Components in People at High-Risk of Developing Schizophrenia: Early Findings from the Edinburgh High-Risk Study. British Journal of Psychiatry, , 180, 179-18.

[37] Murray, V., Mc Kee, I., Miller, P. M., Young, D., Muir, W. J., Pelosi, A. J., \& Blackwood, D. H. (2005). Dimensions and classes of psychosis in a population cohort: a four-class, four-dimension model of schizophrenia and affective psychoses. Psychological Medicine, , 35, 499-510.

[38] Owens, C., Miller, P., Lawrie, S., \& Johnstone, E. C. (2005). Pathogenesis of schizophrenia: a psychopathological perspective. British Journal of Psychiatry, , 186, 386-393.

[39] Pallanti Stefano, Quercioli Leonardo, Hollander Eric.(2004). Social Anxiety in Outpatients with Schizophrenia. A Relevant Cause of Disability. American Journal of Psychology, , 161, 53-58.

[40] Romm, K., Melle, I., Thoresen, C., Andreassen, O., \& Rossberg, J. (2012). Severe social anxiety in early psychosis is associated with poor premorbid functioning, depression and reduced quality of life. Comprehensive Psychiatry, 434 EOF-440 EOF.

[41] Schneier, F., Johnson, J., Horing, C., Liebowitz, A., Weissman, M., \& (2002, . (2002). Social Phobia Comorbidity and Morbidity in an Epidemiological Sample. Archives of General Psychiatry, , 49, 282-288.

[42] Stein, M. B., Walker, J. R., Forde, D. R., \& (1996, . (1996). Public speaking fears in a community sample: Prevalence, impact on functioning, and diagnostic classification, Archives of General Psychiatry, 53, 169-174.

[43] Stein, M., Torgrud, J. L., \& Walker, R. J. (2000). Social Phobia Subtypes, Symptoms and Severity. Arch Gen Ps. ychiatry, , 57, 1046-105.

[44] Tarrier, N. (2005). Co-morbidity and associated clinical problems in schizophrenia: Their nature and implications for comprehensive cognitive-behavioural treatment. Behaviour Change, 125 EOF-142 EOF.

[45] Thornicroft, G., Brohan, E., Rose, D., Sartorius, N., \& Leese, M. (2009). Global pattern of experienced and anticipated discrimination against people with schizophrenia: a cross-sectional survey. The Lancet, 373, 408-415.

[46] Voges, M., \& Addington, J. (2005). Association between social anxiety and social functioning in first-episode psychosis. Schizophrenia Research, , 76, 287-291. 
[47] Wang, P. S., Lane, M., Olfson, M., et al. (2005). Twelve month use of mental health services in the US: Results from the National Comorbidity Survey Replication (NCSR). Archives of General Psychiatry, , 62, 629-640.

[48] Wildenauer, D. B., Schwab, S. G., Maier, W., \& Detera-Wadleigh, S. D. (1999). Do schizophrenia and affective disorder share susceptibility genes? Schizophrenia Research , 39, 107-11.

[49] Wittchen-U, H., Stein, M., \& Kessler, R. (1999). Social Fears and Social Phobia in a Community Sample of Adolescents and Young Adults: Prevalence, Risk Factors and Comorbidity. Psychological Medicine, 29, 309-323.

[50] Wittchen, H. U., Fuetsch, M., Sonntag, H., Muller, N., \& Liebowitz, M. (2000). Disability and quality of life in pure and comorbid social phobia. Findings from a controlled study. European Psychiatry, , 15, 46-58.

[51] Yonkers, K. A., Dyck, I. R., \& Keller, M. B. (2001). An eight-year longitudinal comparison of clinical course and characteristics of social phobia among men and women,. Psychiatric Services, 52 (5), , 637 EOF-43 EOF.

[52] Yung, R. A., Phillips, J. L., Yven, P. H., \& Mc Gorry, P. (2004). Risk Factors for Psychosis in an Ultra-High Risk Group: Psychopathology and clinical features. Schizophrenia Research, 67, 131-152. 